\title{
Remote Monitoring of Drip Irrigation with Microcircuits and Sensors
}

\author{
Parvati Menon \\ Lambert High School, 805 Nichols Rd, Suwanee, GA 30024, USA; menonp2003@gmail.com
}

\begin{abstract}
The goal of this project was to develop an engineering solution to help reduce the difficulties with drip irrigation and to aid farmers with water conservation. Compared to traditional methods, drip irrigation can save over one million gallons of water per acre per year. The main issue highlighted during the study was that the drip lines are located underground and not visible, as farms are located several miles away from the irrigation system. Due to this distance, it is difficult for farmers to monitor if the crop is irrigated as scheduled. This paper shares the development and testing of a prototype that utilized a pressure transducer integrated to a microcontroller to upload information to the cloud and display it through a web portal on a farmer's smartphone. Observations over multiple weeks showed the capability of the system to remotely sense and transmit the operation of drip irrigation. In addition, the simulations showed a system capable of detecting pipe bursts and clogs. Through field observation, the design was modified to be more robust against rodent damage. Overall, this solution eliminated a major hurdle in detecting the functionality of buried irrigation systems by displaying the information remotely at a reasonable cost.

KEYWORDS: Smart Agriculture; Drip Irrigation; Remote Sensing; Buried Irrigation; Water Conversation; Environmental Engineering.
\end{abstract}

\section{- Introduction}

The possible insufficiency of land and water resources to meet the needs of humanity, particularly those pertaining to agriculture, is a pressing issue that is currently affecting roughly a third of the world's population. ${ }^{1}$ Without water, people do not have a means of irrigating their crops and thus cannot provide food for the fast-growing population. According to the International Water Management Institute, agriculture, which accounts for about $70 \%$ of global water withdrawals, is constantly competing with domestic, industrial, and environmental uses for scarce water supplies. In attempts to fix this ever-growing problem, many have tried to develop water management methods that are more effective. ${ }^{1}$

Recent practices in precision agriculture to conserve water usage include two main micro-irrigation methods, which promote increasing water efficiency. The first method is drip irrigation. Drip irrigation, one of the fastest-growing methods of irrigation for high-value crops and orchards, is used on about 73,000 acres in Georgia, mainly in peanut and vegetable farms. Because the water is placed directly at the roots, little is wasted in application. The second method is micro-sprinkler irrigation, which delivers water through a pressurized pipe network to low volume micro-sprinkler heads that spray the water into the air. However, this method is less efficient than the drip method, since more water is lost due to evaporation and runoff. ${ }^{2}$ The table below compares the two irrigation systems Table1. ${ }^{3}$

The critical advantages of drip irrigation systems are the reduced cost of water, the lower energy cost of operating pumps, and decreased usage cost of fertilizer and herbicides. Many farmers can justify the initial investment of drip irrigation based on the savings in water alone.
Farmers today operate many individual plots of land that are distributed over several miles. Due to this geographic spread and the fact that the drip irrigation lines are underground and, thus, not visible, it difficult for farmers to monitor if the crop is irrigated as scheduled. ${ }^{4}$

Table 1: Differentiation of overhead \& drip irrigation systems.

\begin{tabular}{|l|l|l|}
\hline ASPECT & OVERHEAD IRRIGATION & DRIP IRRIGATION \\
\hline $\begin{array}{l}\text { Water Usage } \\
\text { Efficiency (WUE) }\end{array}$ & $75 \%$ & $90 \%$ \\
\hline $\begin{array}{l}\text { Water quality } \\
\text { needed }\end{array}$ & $\begin{array}{l}\text { Water quality should be potable for } \\
\text { the safety of people and animals }\end{array}$ & $\begin{array}{l}\text { Recycled, non-potable water can be safely } \\
\text { used }\end{array}$ \\
\hline Water distribution & Can be patchy & Uniform and controllable \\
\hline Climate & $\begin{array}{l}\text { Suited to areas with unlimited water } \\
\text { and little wind }\end{array}$ & $\begin{array}{l}\text { Suited to water-limited areas, where wind } \\
\text { may contribute to high evaporation }\end{array}$ \\
\hline Erosion & Soils eroded if water pools & Soil erosion minimized \\
\hline Fertilization & $\begin{array}{l}\text { Soil can be fertigated but involves } \\
\text { nutrient wastage }\end{array}$ & Soil can be fertigated without wastage \\
\hline Diseases & $\begin{array}{l}\text { Foliage gets wet and encourages } \\
\text { disease in some crops }\end{array}$ & $\begin{array}{l}\text { Foliage remains dry and less susceptible to } \\
\text { fungal disease }\end{array}$ \\
\hline Weeds & Weeds get as much water as crop & Weeds minimized as water targets crop \\
\hline Costs & $\begin{array}{l}\text { High investment cost, and relatively } \\
\text { high labor and energy costs to } \\
\text { maintain. }\end{array}$ & $\begin{array}{l}\text { Generally has higher investment \& } \\
\text { replacement costs but lower labor and } \\
\text { energy costs. }\end{array}$ \\
\hline
\end{tabular}

\section{Definition of success criteria for proposed solution:}

The success criteria for this project are the development of engineering solutions that help lower the difficulties with drip irrigation and support the expansion of this efficient irrigation method. The solution was developed in two phases.

In phase one, information was gathered on the hurdles faced in the expansion of drip irrigation through literature review and farmer interviews. The literature review was done in two ways. One way was randomly using a search engine. $\mathrm{Pa}-$ pers published by UGA extension services were also utilized and as well as the bibliography cited in those articles. Then, a scientific methodology was applied to prioritize the inputs received from farmer interviews. Based on this priority, a map 
was created to define elements of solutions that are in and out of scope for this project.

In phase two, a prototype was built and tested at a farm at Watkinsville, GA. The prototype's performance was monitored over 45 days and adjustments were made to improve the robustness of the device. The results were analyzed for functionality and to identify next steps.

\section{Explanation of constraints}

The goal of this project was to develop an engineering solution to detect and communicate leaks and clogging in drip irrigation systems. The scope was to develop a prototype that completes the mentioned purpose above and conducts initial validation in a field. The project excludes any design of the initial irrigation system as well as the settings needed for individual crops. The project excluded ways to improve the reliability and reduce damage in the drip irrigation system. For example, there are different methods to reduce the incidence of clogging: water filtration methods and water softeners. These were considered outside the scope of this study Table 3.

\section{Methods}

\section{Exploration of alternatives:}

Phase 1 of this project involved literature review and farmer interviews to understand customer needs and wants related to drip irrigation. The discussions with farmers were used to rank the importance of different needs. There are several Critical to Quality (CTQ's) parameters that can be used in the development of an engineering solution. These CTQs were identified through literature review. By utilizing a Quality Function Deployment (QFD) table, the elements were prioritized that can bring the most impact based on farmer interviews. Quality Function Deployment (QFD) is a structured approach to defining customer needs or requirements and translating them into specific plans to produce products to meet those needs.

A brief explanation of how the table is constructed Table 2: The Customer Needs are listed vertically in the first column and all related CTQ's are listed horizontally across the top. In the second column, 1 to 5 is assigned based on the importance of the Needs, where 5 is the most critical to the farmer. This ranking is based on the VOC (Voice of Customer) data received from farmer interviews. Next, each CTQ is scored on how strongly it correlates to each Need by the author. A score of 5 is used for a strong correlation and 1 for a weak one. Finally, the importance rating for the Needs is multiplied by the correlation score for each CTQ and the scores are added up vertically for each CTQ. Once the scores are computed for all CTQs, the ones with the highest scores are selected for action.

"Flow monitoring" was the CTQ best able to meet the farmer's needs with "Remote user interface the next highly scored. The QFD table shows developing a remote flow monitoring system in drip irrigation could address multiple concerns of priority for the farmers related to the functioning status of the irrigation system.

There are different design ideas to make the solution more complete. However, these design ideas could also make the project and solution more complex. The focus of this project was to validate a solution to remotely sense and communicate the functioning of the systems and to check for leaks and clogging. As an example, a closed-loop system with moisture sensing that can create a hands-off system could be a clear next phase for this project.

Table 2: QFD chart.

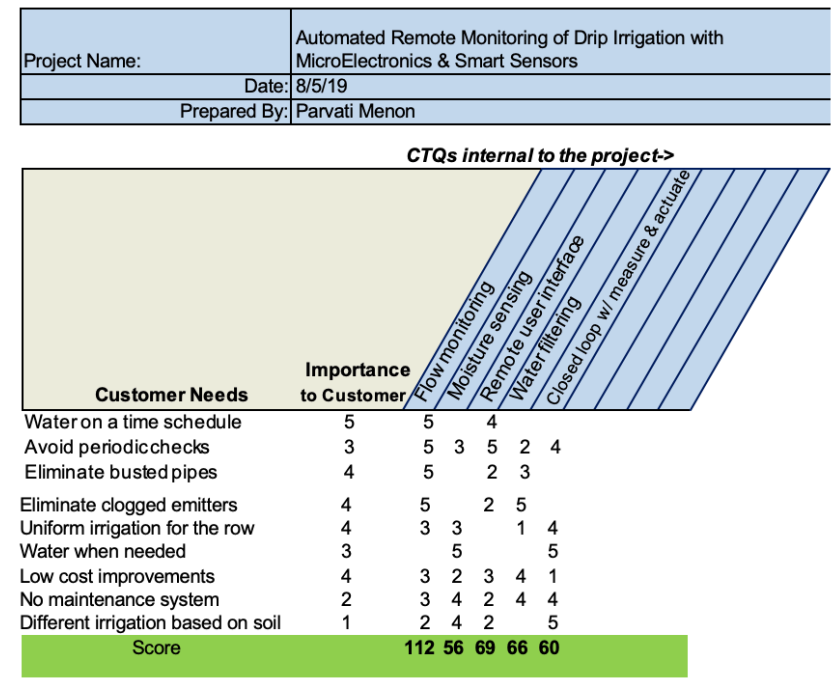

Table 3: Scope for the project.

\begin{tabular}{lccc}
\hline \multicolumn{1}{c}{ Design } & In Scope & In Scope (future) & Out of Scope \\
\hline Flow monitoring & $\mathrm{X}$ & & \\
\hline Moisture sensing & & $\mathrm{X}$ & \\
\hline Remote user interface & $\mathrm{X}$ & & $\mathrm{X}$ \\
\hline Water filtration & & & \\
\hline Closed loop system & & $\mathrm{X}$ & \\
\hline
\end{tabular}

Based on this table, the prototype development focused on remotely monitoring flow in the drip irrigation system, integrating it to Trellis micro-controller system for uploading to the cloud and displaying that to the farmer's smartphone.

\section{Identification of a solution:}

The solution entailing remote flow monitoring requires a sensor to monitor flow in the field, a microprocessor system to receive and transmit the sensor signal, and a cloud-based reporting tool to share the information in a user-friendly way to farmers.

\section{Sensor selection:}

Flow monitoring for closed systems similar to drip irrigation can be done at relatively low-cost using pressure transducers or mechanical flow meters. ${ }^{5}$ Table 4 compares the merits of each system relative to project requirements.

The pressure transducer was selected due to its versatility in low flow conditions and lower cost.

\section{Development of Prototype/Prototype construction:}

The Trellis microcontroller system and web portal were utilized as the platform to receive and communicate the signal from the pressure transducer. Coding was done to convert pressure transducer voltage to transmit pressure ( $\mathrm{psi}$ ) information with a timestamp to the cloud-based server and to 
display the graphs. The basic layout of this system is shown in Figure 1 below.

Table 4: Merits of flow monitoring sensors.

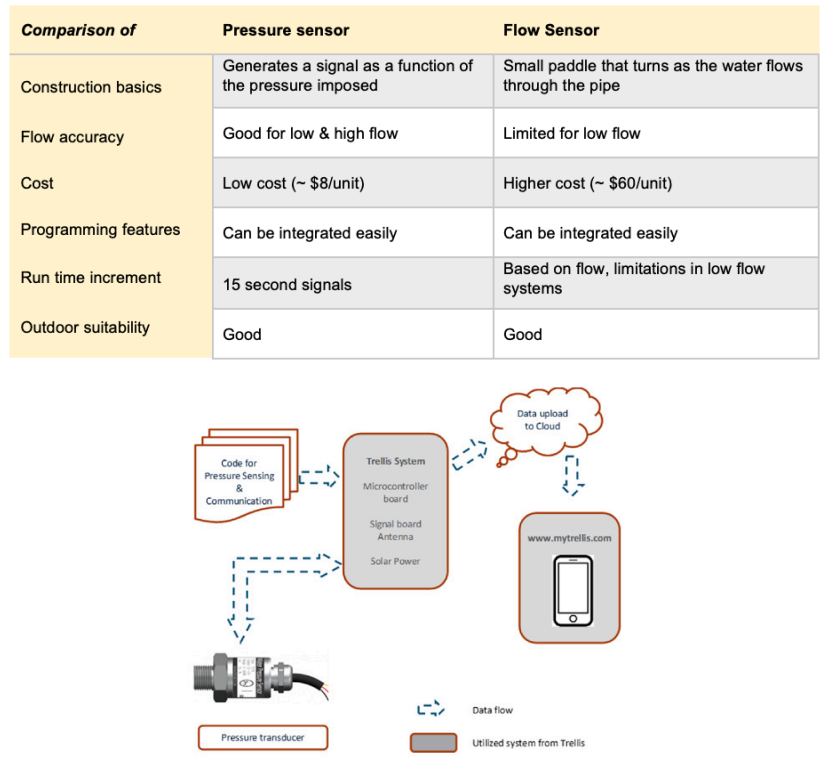

Figure 1: Basic layout of prototype system.

The experiment was conducted at a farm in Georgia (1390 Salem Rd, Watkinsville, GA). This field operates as a nursery, and it was growing crape myrtles during the experiment. The schematic of the irrigation systems is shown in Figure 2-7.
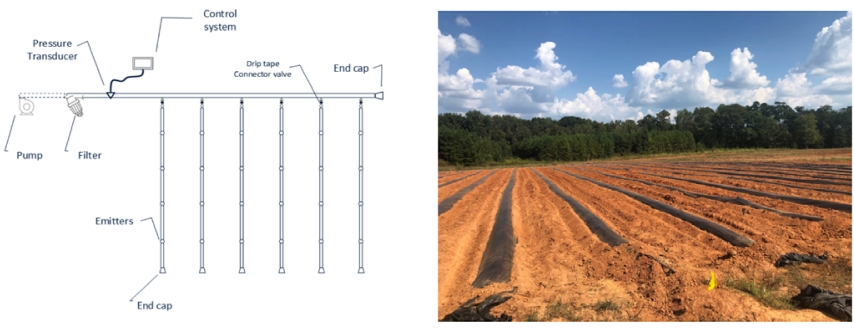

Figure 2: Basic schematic of drip irrigation system system.

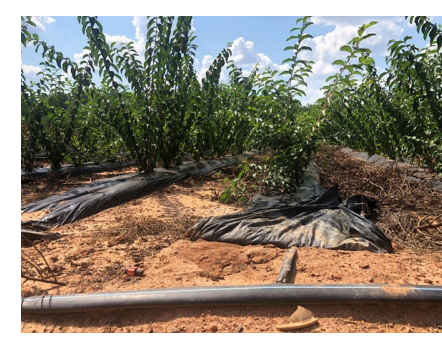

Figure 4: Drip irrigation site with prototype installed.

\section{Trial Design :}

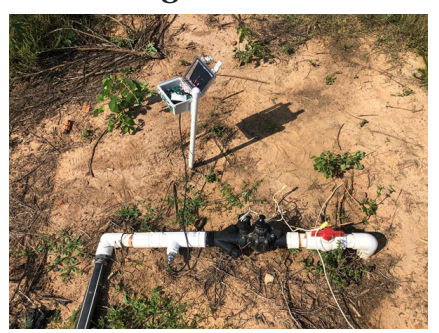

Figure 5: Initial Installation.

The initial data collection involved the following validation steps. The pump was turned on and off to evaluate the pressure in the system. The expected pressure in the system is around 25psi. Next, scenarios were created to simulate leaks and clogs. To simulate leaks, one of the end caps was opened and closed after a couple of minutes. To simulate a clog, one of the drip lines was pinched and then opened. The system was monitored over four weeks to ensure proper functioning. The graphs from the experiment are shown below.

\section{Results and Discussion}

Trial Results \& Discussion :

(Charts Sequenced Over Time).
Chart 1: Pump start, pressure stabilizing around $25 \mathrm{psi}$.

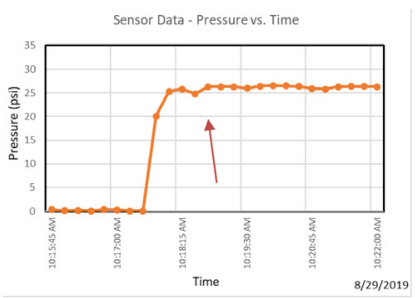

Chart 3: Pump stops, pressure drops to zero.

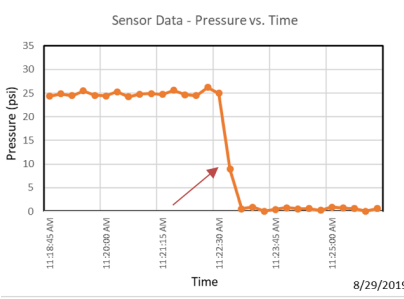

Chart 5: (replication) Pumb starts, pressure stablizing around 25 psi. Sensor Data - Pressure vs. Time

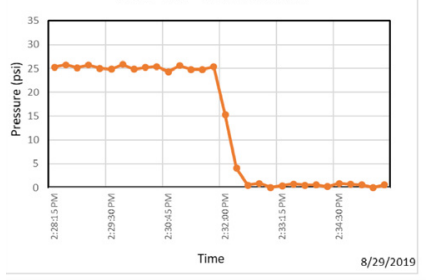

Chart 2: Leak created-detectable pressure drops of $5 \mathrm{psi}$.

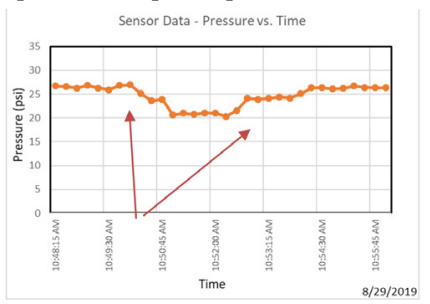

Chart 4: Clog created-detectable pressure increase of $6 \mathrm{psi}$.

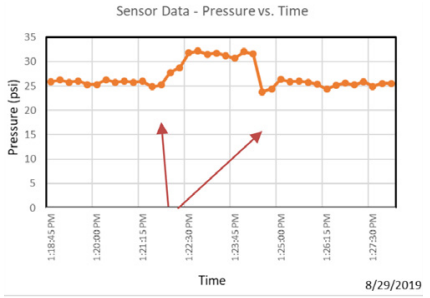

Chart 6: Pumb starts, pressure stablizing around 25 psi.

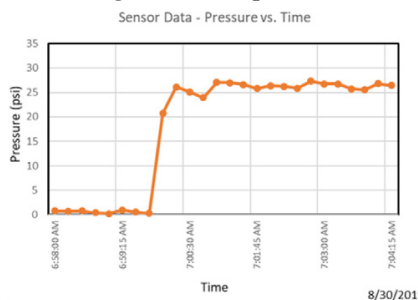

Charts 1-4 shows trials done at the beginning of the experiment to simulate clogs and leaks.

The normal variation in steady state $+/-3$ psi, thus a clog or a leak would be indicated by a higher pressure differential.
Chart 7: Pumb starts, pressure stabilizing around 25 psi.

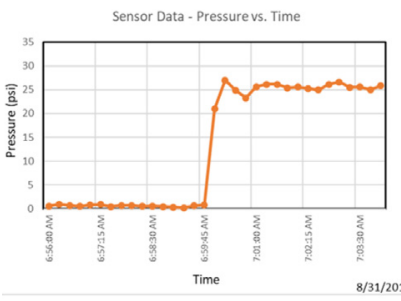

Chart 9: Pumb starts, pressure stabilizing around $25 \mathrm{psi}$. Sensor Data - Pressure vs. Time

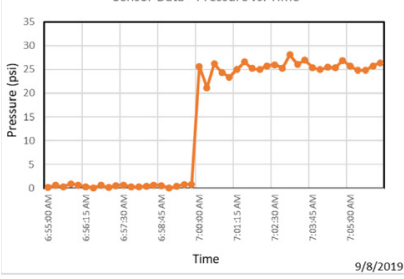

Chart 8: Pumb starts, pressure stablizing around 25 psi.

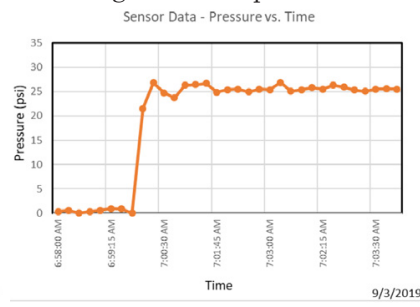

Chart 10: No data recorded in the system.

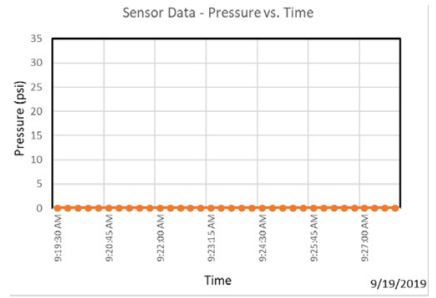

The pump was set to be turned on at 7 am daily. A few charts (6-9) were selected to show the pump operation over several days (replication). 
The checks above showed the system was functioning normally. However, the data from 9/19/19 showed an anomaly with zero pressure throught the day.

This protype was field tested for about two months and recieved favorable responses from the farmer and agricultural specialists. This solution will help expand drip irrigation.

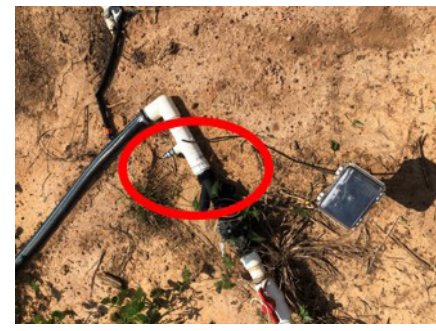

Figure 6: Possible rodent damage.

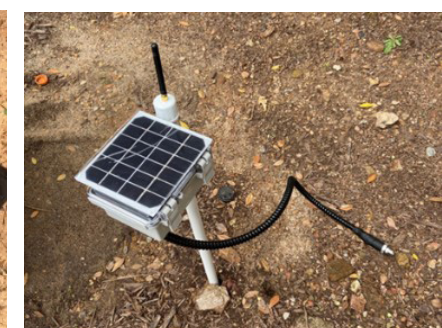

Figure 7: Modified cable:
Investigation in the field showed damage, possibly from rodent activity, to the wire connecting transducer to the control board. The cut table was replaced with an industrial grade rubber conduit cable that is more robust.

\section{Economics of remote sensing of drip irrigation :}

Studies conducted by the University of Georgia ${ }^{4}$ and by the University of California, Santa Barbara ${ }^{6}$ for peanut farmers in Georgia and fruit growers in the Central Valley, respectively, show significant improvement in profitability due to drip irrigation. The UGA study has quantified the profit improvement of precision agriculture at $\$ 301$ acre just on water savings. Drip irrigation also has the additional benefit of reduced fertilizer and herbicide costs compared to overhead applications. By utilizing the drip irrigation pipes $\&$ emitters, the fertilizer is targeted to the roots and has significantly lower waste. Herbicide usage is lower in drip-irrigated farms as the areas without crops stay dry, thereby, limiting weed growth.

Based on the cost of Trellis microcontroller, pressure transducer, piping, and labor, the installed cost of the remote sensing system is estimated to be $\$ 200 /$ unit. This is a payoff of less than one year based on water savings (about $\$ 300$ / acre). Thompson and Porter at UGA7 estimate the life of drip irrigation systems to be 10 to 15 years. This makes the investment payoff attractive to the farmer.

\section{- Conclusion}

Overall, this project addresses a significant environmental issue of water scarcity. Drip irrigation can save millions of gallons of water. By capturing the voice of customers, I was able to prioritize critical hurdles that are faced to explain this efficient irrigation method. This solution eliminated a major hurdle for detecting the functionality of buried irrigation systems by collecting and viewing the information remotely at a reasonable cost. This protype was field tested for about two months and received favorable responses from the farmer and agricultural specialists. This solution will help expand drip irrigation. A 50-60\% water savings from drip irrigation will translate to a million gallon in water savings per year per acre.

\section{Acknowledgements}

TI would like to thank Mr. Adam Snow and Ms. Liz Buchen at Trellis Inc. They employed me as an intern and mentored me in the development of this project. I received valuable input from Dr. George Vellidis (Professor, University of Georgia) and Mr. Michael Porter (Cooperative Extension precision agriculture and irrigation specialist, University of Georgia). I am inspired by Mrs. Jessica Ventre's AP Environmental Sciences class and was exposed to real-world challenges taxing our fragile environment by rapid industrialization and overpopulation. I also want to thank Mrs. Ventre and my dad, Ravishankar Menon, for their critique of my paper and probing questions during my research.

\section{References}

1. Hoekstra A Y; Mekonnen M; The water footprint of humanity; Proc. Natl Acad. Sci. USA 2012,109 3232-7.

2. Hook, James E; "Irrigation" New Georgia Encyclopedia; 2018. Web. 03 October 2019.

3. Hawkins, HJ; Stanway R; The Sustainable Dairy Handbook: For SA Dairy Farmers; 2013.

4. Wesley Porter; Calvin D. Perry; Bulletin882 - Factors to Consider in Selecting a Farm Irrigation System; 2015.

5. Ling, Al; Fluid Flow Measurement Selection and Sizing; March 2007. http://www.idconline.com/technical_references/pdfs/ instrumentation/Fluid_Flow_Measurement_Selection_and Sizing.pdf .

6. Caswell, Margriet, D. Zilberman, G.E. Goldman. Economic implications of drip irrigation; California Agriculture; 1984.

7. Thompson, Clint; Sub-surface drip irrigation a possible solution for some Georgia peanut farmers; University of Georgia, Extension Publications; 2015.

\section{Author}

Parvati Menon, Rising Senior, Lambert High School, Suwanee, GA. Parvati is passionate about technology and the environment. She wants to pursue a career in Computer Engineering with a focus on water conservation. Parvati's community work with underprivileged students to promote STEM was recognized by the National Academy of Engineering. 